\title{
PROTECTIVE ROLE OF VITAMIN E AND VITAMIN C ON MORPHOLOGY OF GASTRIC MUCOSAL INJURY INDUCED BY ASPIRIN IN ALBINO RATS
}

\author{
IRAM ATTA, SHAZIA TUFAIL, RAAFEA TAFWEEZ \\ Department of Anatomy, King Edward Medical University
}

\begin{abstract}
Background: Peptic ulcer has become an immense problem in our health care system. One of the major causes being the overuse of NSAIDs in Pakistan.

Objective: To evaluate gastro protection by Vitamin E, Vitamin C and combination of Vitamin E and Vitamin C on morphology of aspirin induced gastric mucosal injury in albino rats.

Methodology: 45 adult albino rats were taken and organized into 5 groups. Control was formed by Group I. Group II was given aspirin. Group III was given Vitamin C and aspirin. Group IV was given Vitamin E and aspirin. Group V received Vitamin C, Vitamin E and aspirin. All the doses were given for 14 days. Rats were then sacrificed after 24 hours and their stomachs were examined to compare the gross and histological findings regarding the color of the gastric mucosa, presence of gastric ulcer, site of the ulcer, epithelial integrity and extent of the ulcer.

Results: Increased frequency of ulcers extending into the submucosa were found in group given aspirin as compared to the rest of the groups. The group that was given combination of Vitamin $\mathrm{E}$ and Vitamin $\mathrm{C}$ along with aspirin showed significantly better condition than all the groups by showing normal mucosa and intact epithelium in most of the animals.

Conclusion: Combination of Vitamin $\mathrm{E}$ and Vitamin $\mathrm{C}$ has greater defensive effect on aspirin induced gastric mucosal insult than Vitamin C or Vitamin E alone by showing reduction in frequency and severity of gastric ulcer.
\end{abstract}

Keywords: Aspirin, Vitamin C, Vitamin E

How to cite this article: Atta I, Tufail S, Tafweez R. Maternal literacy and malnutrition in children: A comparative study. Pak Postgrad Med J 2020;31(1): 8-13

This is an Open Access article distributed under the terms of the Creative Commons Attribution License (http://creativecommons.org/licenses/by/3.0), which permits unrestricted use, distribution, and reproduction in any medium, provided the original work is properly cited.

DOI: HTTPS//DOI.ORG/10.51642/ppmj.v31i01.340

Correspondence to: Aram Atta,

Demonstrator, Department of Anatomy, King Edward Medical University, Lahore, Pakistan.

Email: iram343@gmail.com

\section{INTRODUCTION}

Peptic ulcer is injury of the digestive tract that leads to the interruption of the epithelium. ${ }^{1}$ It is commonly caused by the disproportion between the aggressive (pepsin, acid, NSAIDS helicobacter pylori, oxidative stress and ethanol) and defensive factors (mucus secretion, bicarbonate, epidermal growth factors, prostaglandin, cellular regeneration and blood flow). ${ }^{[2,3]}$ Aspirin is widely available as an anti-inflammatory, antipyretic and analgesic agent. ${ }^{4}$ Around 40,000 tonnes is being used each year for the treatment of diseases like rheumatic arthritis, rheumatoid fever, pericarditis, and Kawasaki disease ${ }^{5}$ Aspirin induces gastric mucosal injury by inhibiting cyclooxygenase and releasing endothelin-1 (ET-1), which is a potent vasoconstrictor shown to induce mucosal injury.$^{2}$ It also inhibits mucus and bicarbonate secretion. ${ }^{6-7}$ Aspirin increases neutrophil infiltration that lead to excessive release of oxygen radicals and enhance lipid peroxidation which causes microvascular injury in gastric mucosa. ${ }^{[7,8,9]}$ .Water soluble Vitamin $C$ is present in wide range of foods like cabbage, lemons, oranges, broccoli, tomatoes and potatoes. ${ }^{10}$ Radicals such as superoxide, hydroxyl, and lipid hydro peroxide which are known to damage the gastric mucosa are scavenged by the Vitamin C. ${ }^{3}$ The function of endogenous free-radical scavengers such as superoxide dismutase, catalase and glutathione peroxidase is also elevated by Vitamin C . ${ }^{2}$ Lipid soluble Vitamin $\mathrm{E}$ is an antioxidant that is present in peanuts, almonds, sunflower seeds, walnuts, pecans, pistachios, palm oil and sesame seeds. ${ }^{11}$ Vitamin E acts as a chain breaking antioxidant that maintains cellular integrity by removing reactive oxygen radicals .2 Vitamin $\mathrm{E}$ acts by disrupting chain initiation and extension of free-radical reactions and lipid 
peroxidation in cell membranes. ${ }^{2}$ Vitamin $E$ and Vitamin $\mathrm{C}$ co-administration reduces gastric acid secretion and increases mucus output both of which are important mechanism in preventing formation of gastric ulcers. ${ }^{10}$ Both these vitamins are physiological antioxidants that reduce oxidative stress by donating their electrons and stopping other compounds from being oxidized. ${ }^{12}$ This research is endeavored to compare the effects of Vitamin C, Vitamin E and combination of Vitamin C and Vitamin $\mathrm{E}$ against aspirin induced gastric mucosal injury.

\section{METHODS}

Forty-Five active adult Sprague Drawly male albino rats were taken in accordance with International and Institutional guidelines and all procedures were approved by the Ethical Committee of King Edward Medical University, Lahore. They were kept in the Experimental Research Lab (Animal House) of Post Graduate Medical Institute, Lahore under controlled conditions of temperature $\left(25 \pm 2^{\circ} \mathrm{C}\right)$, relative humidity $(60 \pm 5 \%)$ and 12 hours of light/dark cycles for 7 days. Food and water was given ad libitum. Aspirin, Vitamin $\mathrm{C}$ and Vitamin $\mathrm{E}$ were purchased in form of stock solution containing $60 \mathrm{mg} / \mathrm{ml}, 20 \mathrm{mg} / \mathrm{ml}$ and $360 \mathrm{mg} / \mathrm{ml}$ concentrations respectively from Pakistan Council of Scientific and Industrial Research (PCSIR), Lahore. Animals were randomly divided into five groups of 9 animals each. Group I(control) received only distilled water, Group II was given single oral dose of aspirin $300 \mathrm{mg} / \mathrm{kg}$, Group III was given single oral dose of vitamin C $10 \mathrm{mg} / 100 \mathrm{~g}$ body weight, Group IV was given single oral dose of vitamin E 400IU/100g body weight and Group V were given combination of vitamin $\mathrm{C}$ $10 \mathrm{mg} / 100 \mathrm{~g}$ body weight and vitamin E 400IU/100g body weight .Then after an interval of one hour single oral dose of aspirin $300 \mathrm{mg} / \mathrm{kg}$ was given to Group III,IV and $\mathrm{V}$ daily by oral gastric gavage method for 14 days. ${ }^{[3,13]}$ Animals were dissected after 24 hours of their last dose. All the stomachs were dissected along the greater curvature and were then washed with normal saline. Their stomachs were observed for changes in colour of the gastric mucosa, presence of gastric ulcer and site of the ulcer. The specimen of all animals of each group were placed in separate labelled plastic jars containing formalin $10 \%$ for 48 hours. Stomachs were cut transversely and tissue strips containing ulcers were separated. The sections were stained with Hematoxylin and Eosin and slides were studied under the light microscope at magnification of $10 \mathrm{X}$ and $40 \mathrm{X}$ to observe changes in epithelial integrity and extent of ulcer. Data was entered and analyzed by using SPSS -21-. Comparison of five groups was made by applying one way ANOVA. Post hoc tukey and likelihood ratio tests were applied to compare the association between the groups. P-value $\leq 0.05$ was taken as significant.

\section{RESULTS}

Group I (control) showed normal shinny pink gastric mucosa with no congestion. In Group II (Aspirin) grayish pink in 6(66.7\%) and dull red gastric mucosa in 3(33.3\%) rats were seen. Group-V (Vit $\mathrm{C}+\mathrm{VitE}+$ Aspirin) had 8(88.9\%) pink mucosae while in group-III (VitC +Aspirin) and IV (VitE+Aspirin) this number was $4(44.4 \%)$ and $6(66.7 \%)$ respectively. Group-V had no significant difference from the control group ( $\mathrm{p}$-value $=0.229$ ), as well as had insignificant difference from that of group-III and IV with p-values 0.097 and 0.248 respectively. All three treatment groups had significant difference from the induced group (group-II) with p-values 0.030, 0.001 and $<0.001$ respectively (Table 1, Fig 1). No gastric ulcer was seen in Group I(control). All the animals in Group II(Aspirin) produced gastric ulcers.

There were 5(55.5\%) animals with gastric ulcer present in group-III (VitC +Aspirin), and 3(33.3\%) and $1(11.1 \%)$ in group IV (VitE+Aspirin) and V (Vit C+VitE + Aspirin) respectively. The presence of ulcers in Group $\mathrm{V}$ (Vit $\mathrm{C}+\mathrm{VitE}+\mathrm{Aspirin})$ was significantly different from the rest of the groups with p-value $<0$. 001(Table 2 ). The group I (Control) had no ulcer so the site of ulcer was not applicable, similarly 4, 6 and 8 animals in group III (VitC +Aspirin), IV (VitE+Aspirin) and V (Vit $\mathrm{C}+\mathrm{VitE}+\mathrm{Aspirin}) \mathrm{had}$ no ulcers. The cases with ulcers in group II (Aspirin) were found in body for 4(44.4\%) and $5(55.5 \%)$ in pylorus, while in group III (VitC +Aspirin), this ratio was 2 and 3 respectively. Ulcers in $3(33.3 \%)$ animals of group IV (VitE+Aspirin) and 1 $(11.1 \%)$ of group $\mathrm{V}$ (Vit $\mathrm{C}+\mathrm{VitE}+\mathrm{Aspirin})$ were found in pylorus only. The difference overall among groups was found significant (Table 3). The epithelium was intact for all animals in group I(Control). It was disrupted in 5(55.5\%), 3(33.3\%) and $1(11.1 \%)$ of group III (VitC +Aspirin), IV (VitE+Aspirin) and V (Vit $\mathrm{C}+\mathrm{VitE}$ Aspirin) respectively. The group $\mathrm{V}(\mathrm{Vit} \mathrm{C}+\mathrm{VitE}$ + Aspirin) displayed notable difference from all the other groups (Table 4). The ulcers found in group IV (VitE+Aspirin) and group $\mathrm{V}$ (Vit $\mathrm{C}+\mathrm{VitE}+$ Aspirin) only extended up to the epithelium. Three ulcers of group III (VitC +Aspirin), extended to the epithelium, and other two up to submucosa, while in group II(Aspirin), two reached epitheliums, five submucosa and other two penetrated the muscularis propria. All three treatment groups had significantly better condition as compared to group II(Aspirin) in terms of extent of ulcer with p-values $0.020,<0.001$ and $<0.001$ in order respectively (Table 5 . Fig 2 ). 
Table 1 Color of gastric mucosa and its comparison among various groups

\begin{tabular}{lcccccccc}
\hline \multirow{2}{*}{ Group } & \multicolumn{9}{c}{ Color of gastric Mucosa } \\
\cline { 2 - 10 } & \multicolumn{2}{c}{ Grayish pink } & \multicolumn{2}{c}{ Pink } & \multicolumn{2}{c}{ Dull Red } & \multicolumn{2}{c}{ Total } \\
& $\mathrm{n}$ & $\%$ & $\mathrm{n}$ & $\%$ & $\mathrm{n}$ & $\%$ & $\mathrm{n}$ & $\%$ \\
\hline Group - I & 0 & 0.0 & 9 & 100.0 & 0 & 0.0 & 9 & 100.0 \\
Group - II & 6 & 66.7 & 0 & 0.0 & 3 & 33.3 & 9 & 100.0 \\
Group - III & 4 & 44.4 & 4 & 44.4 & 1 & 11.1 & 9 & 100.0 \\
Group - IV & 3 & 33.3 & 6 & 66.7 & 0 & 0.0 & 9 & 100.0 \\
Group - V & 1 & 11.1 & 8 & 88.9 & 0 & 0.0 & 9 & 100.0 \\
\hline
\end{tabular}

Chi-square $=33.08 \quad$ P-value $<0.001$

Table 2 Status of gastric ulcer in mucosa and its comparison among various groups

\begin{tabular}{lcccccc}
\hline \multirow{2}{*}{ Group } & \multicolumn{9}{c}{ Gastric ulcer } \\
\cline { 2 - 8 } & $\mathrm{n}$ & Present & $\mathrm{n}$ & Absent & $\mathrm{n}$ & Total \\
\hline Group - I & 0 & 0.0 & 9 & 100.0 & 9 & 100.0 \\
Group - II & 9 & 100.0 & 0 & 0.0 & 9 & 100.0 \\
Group - III & 5 & 55.6 & 4 & 44.4 & 9 & 100.0 \\
Group - IV & 3 & 33.3 & 6 & 66.7 & 9 & 100.0 \\
Group - V & 1 & 11.1 & 8 & 88.9 & 9 & 100.0 \\
\hline
\end{tabular}

Chi-square $=30.47 \quad$ P-value $<0.001$

Table 3 Site of ulcer in gastric mucosa and its comparison among various groups

\begin{tabular}{|c|c|c|c|c|c|c|c|c|}
\hline \multirow{3}{*}{ Group } & \multicolumn{8}{|c|}{ Site of ulcer } \\
\hline & \multicolumn{2}{|c|}{ Body } & \multicolumn{2}{|c|}{ Pylorus } & \multicolumn{2}{|c|}{ NA } & \multicolumn{2}{|c|}{ Total } \\
\hline & $\mathrm{n}$ & $\%$ & $\mathrm{n}$ & $\%$ & $\mathrm{n}$ & $\%$ & $\mathrm{n}$ & $\%$ \\
\hline Group - I & 0 & 0.0 & 0 & 0.0 & 9 & 100.0 & 9 & 100.0 \\
\hline Group - II & 4 & 44.4 & 5 & 55.6 & 0 & 0.0 & 9 & 100.0 \\
\hline Group - III & 2 & 22.2 & 3 & 33.3 & 4 & 44.4 & 9 & 100.0 \\
\hline Group - IV & 0 & 0.0 & 3 & 33.3 & 6 & 66.7 & 9 & 100.0 \\
\hline Group - V & 0 & 0.0 & 1 & 11.1 & 8 & 88.9 & 9 & 100.0 \\
\hline
\end{tabular}

Table 4 Integrity of epithelium in gastric mucosa of various groups

\begin{tabular}{|c|c|c|c|c|c|c|}
\hline \multirow{3}{*}{ Group } & \multicolumn{6}{|c|}{ Epithelium Integrity } \\
\hline & \multicolumn{2}{|c|}{ Intact } & \multicolumn{2}{|c|}{ Disrupted } & \multicolumn{2}{|c|}{ Total } \\
\hline & $\mathrm{n}$ & $\%$ & $\mathrm{n}$ & $\%$ & $\mathrm{n}$ & $\%$ \\
\hline Group - I & 9 & 100.0 & 0 & 0.0 & 9 & 100.0 \\
\hline Group - II & 0 & 0.0 & 9 & 100.0 & 9 & 100.0 \\
\hline Group - III & 4 & 44.4 & 5 & 55.6 & 9 & 100.0 \\
\hline Group - IV & 6 & 66.7 & 3 & 33.3 & 9 & 100.0 \\
\hline Group - V & 8 & 88.9 & 1 & 11.1 & 9 & 100.0 \\
\hline
\end{tabular}

Chi-square $=30.47 \quad$ P-value $<0.001$

Table 5 Extent of ulcer in gastric mucosa and its comparison among various groups

\begin{tabular}{lcccccccccc}
\hline & \multicolumn{8}{c}{ Extent of ulcer } \\
\cline { 2 - 12 } \multicolumn{1}{c}{ Group } & \multicolumn{2}{c}{ Epithelial } & \multicolumn{2}{c}{ Submucosal } & \multicolumn{2}{c}{ Muscularis } & \multicolumn{2}{c}{ NA } & \multicolumn{2}{c}{ Total } \\
& $\mathrm{n}$ & $\%$ & $\mathrm{n}$ & $\%$ & $\mathrm{n}$ & $\%$ & $\mathrm{n}$ & $\%$ & $\mathrm{n}$ & $\%$ \\
\hline Group - I & 0 & 0.0 & 0 & 0.0 & 0 & 0.0 & 9 & 100.0 & 9 & 100.0 \\
Group - II & 2 & 22.2 & 5 & 55.6 & 2 & 22.2 & 0 & 0.0 & 9 & 100.0 \\
Group - III & 3 & 33.3 & 2 & 22.2 & 0 & 0.0 & 4 & 44.4 & 9 & 100.0 \\
Group - IV & 3 & 33.3 & 0 & 0.0 & 0 & 0.0 & 6 & 66.7 & 9 & 100.0 \\
Group - V & 1 & 11.1 & 0 & 0.0 & 0 & 0.0 & 8 & 88.9 & 9 & 100.0 \\
\hline
\end{tabular}

Chi-square $=40.32 \quad$ P-value $<0.001$ 

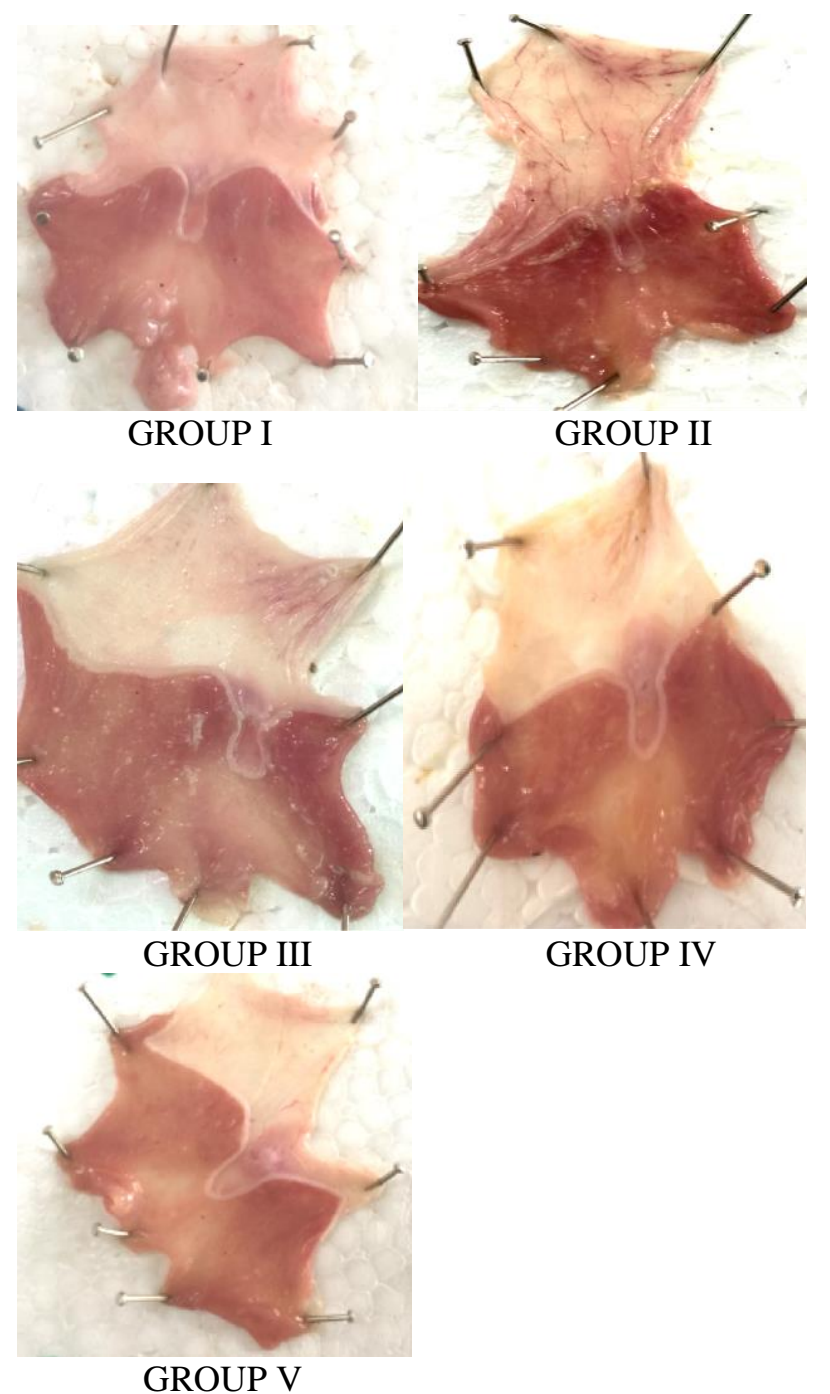

FIG.1Photograph showing different colors of gastric mucosa that was observed in all five groups of experiment.

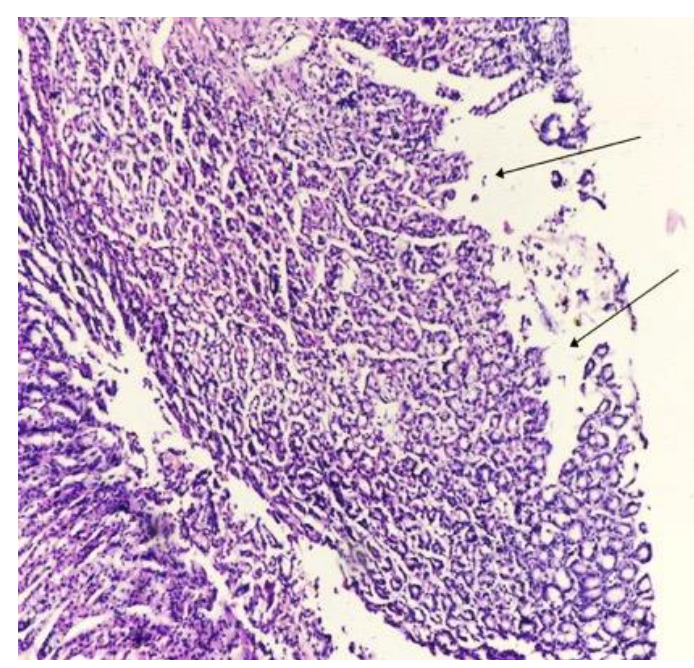

Epithelial

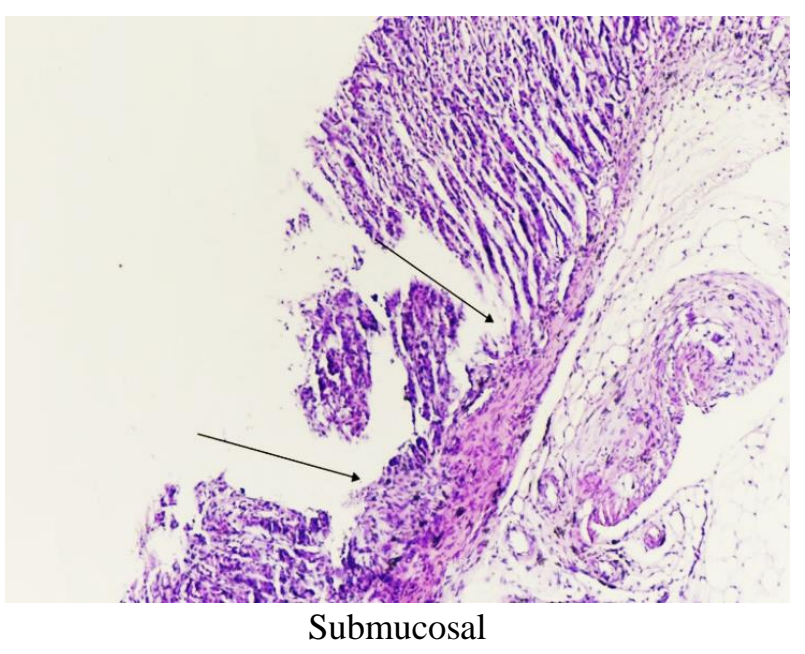

FIG.2 Photomicrograph showing ulcer in epithelial and submucosal region at $10 \mathrm{X}$. Magnification $10 \times 10$ $=100$

\section{DISCUSSION}

The result of the present study is in consensus with the confirmed finding that Aspirin is commonly used for induction of ulcer and it leads to intense gastric mucosal injury. ${ }^{7}$ Vitamin $\mathrm{E}$ and Vitamin $\mathrm{C}$ both act as antioxidants by scavenging the free radicals and have a protecting effect on the gastric mucosa. ${ }^{(10,11)}$. Previous studies suggest that the Aspirin induced injury to the gastric mucosa initiates with microvascular injury that disrupts the vascular endothelium and results in increased vascular permeability, oedema and epithelial lifting. ${ }^{2}$ The color of gastric mucosa varied from pink to grayish pink in all Groups except Group- II(Aspirin) that showed dull red mucosa. These findings are consistent with Angel Lanas et al. (2017) who showed similar results and established the relation of red color mucosa caused by NSAIDs that disrupt mucus phospholipids and cell membrane by uncoupling of mitochondrial oxidative phosphorylation and lead to vascular damage. ${ }^{1}$ In this research the gastric ulcer was present in all animals given Aspirin only and Group $\mathrm{V}$ (Vit C+Vit E+Aspirin) showed least number of ulcer as compared to all the groups (table2). Pohle et al. (2001) also explored the fact that Aspirin inhibits prostaglandins that increase the acid back diffusion and microvascular injury along with neutrophils activation that leads to increase number of free radicals that contribute in the formation of gastric ulcers. ${ }^{13}$ Moreover Vivian Molina Cuevas et al. (2011) also showed similar results of reduced number of ulcers in rats that were given Vitamin $\mathrm{C}$ and Vitamin $\mathrm{E}$ as both antioxidants reduce lipid peroxidation in the gastric mucosa, which preserves the gastric microcirculation ${ }^{3}$ In present study, most of the ulcers were found in the pyloric region of stomach which is in consonant with Joseph Eichensher et al. (2018)who discovered similar results that the common site of gastric ulcer is the pylorus on lesser curvature near the junction between 
body and antrum. ${ }^{14} \mathrm{G}$ cells produce peptide hormone Gastrin in pyloric antrum that activates the parietal cells to release hydrochloric acid. ${ }^{1}$ As a result the pyloric part becomes more susceptible due to the increased level of hydrochloric acid that acts together with aspirin to increase the secretions of gastric acid. ${ }^{1}$ Histological examination in present study revealed that epithelium was disrupted by the use of Aspirin. This study coincides with the study of Zhongzhi Wang et al. (2011) in which ulcers were found with distorted gastric glands, disrupted mucosal epithelium and inflammatory exudates in the stomachs of the rats treated with aspirin.${ }^{15}$ Most of the stomachs that were given combination of Vitamin $\mathrm{C}$ and Vitamin $\mathrm{E}$ showed intact epithelium as compared to Vitamin C and Vitamin E alone along with Aspirin .Similarly Qing Jiang(2014) also commented on the protective effect of Vitamin E on epithelium of gastric mucosa by increasing the amount of mucus output and reducing the free radicals produced by NSAIDs. ${ }^{11}$ Both Vitamin $\mathrm{C}$ and Vitamin $\mathrm{E}$ are antioxidants that combat the effects of lipid peroxidation and decrease oxidative stress by donating their electrons and prevent other compounds from being oxidized. ${ }^{16}$ The extent of the ulcers in different groups varied (table 5,fig 5).The ulcers shown in Group III(VitC+Aspirin), IV (VitE+Aspirin) and $\mathrm{V}(\mathrm{VitC}+\mathrm{VitE}+$ Aspirin) only extended up to the epithelium whereas ulcers produced by aspirin penetrated the muscularis mucosae. The present study is similar to the study of Oladunni $\mathrm{O}$. Otanwa et al (2015) who suggested that vitamin E acts as a universal stabilizer of biological membranes and its supplementation reduces the extent of ulcers. It protects the mucosal barrier by inhibiting lipid peroxidation. ${ }^{2}$ John L. Wallace (2008) proved that NSAIDs reduce bicarbonate and mucus secretion, thereby reducing the potency of the juxta mucosal $\mathrm{pH}$ gradient in preserving the epithelium. ${ }^{(17)}$

\section{CONCLUSION}

The study revealed that combination of Vitamin $\mathrm{E}$ and Vitamin $\mathrm{C}$ showed greater gastro protective effect on aspirin induced gastric mucosal injury by producing significantly a smaller number of ulcers with less severity as compared to Vitamin $\mathrm{C}$ and Vitamin $\mathrm{E}$ alone. Synergistic effects of Vitamin $\mathrm{C}$ and $\mathrm{E}$ have been relatively studied less and there is still need to compare the combined effects of antioxidants to determine their possible collaborative effects.

\section{ETHICAL APPROVAL}

The study was approved by the Ethical Review Committee of King Edward Medical, Lahore, vide reference No. 203/RC/KEMU dated March 12, 2018.

\section{REFERENCES}

1. Lanas A, Chan FK. Peptic ulcer disease. The Lancet. 2017 Aug 5;390(10094):613-624.

2. Otanwa OO, Umar IA, Owolabi OA. Effect of zinc and vitamin e on some biochemical and histological changes in the gastric mucosa of ethanol induced ulcerogenic rats. Int $\mathbf{J}$ Tech Res Appl. 2015;3(6) 49-56.

3. Ardalani H, Hadipanah A, Sahebkar A. Medicinal plants in the treatment of peptic ulcer disease: a review. Mini Reviews in Medicinal Chemistry. 2020 Apr 1;20(8):662-702.

4. Katzung BG, Masters SB, Trevor AJ. Basic and Clinical Pharmacology chapter 36 NSAIDS. $13^{\text {th }}$ edition. United States of America. Mc Graw Hill. 2015. P 508-520.

5. Aspirin [updated2017, cited2017] available from https://en.wikipedia.org/windex.php?title=Aspirin\& oldid $=802554229$.

6. Magierowski M, Magierowska K, Surmiak M, Hubalewska-Mazgaj M, Kwiecien S, Wallace JL, et al. The effect of hydrogen sulfide-releasing naproxen (ATB-346) versus naproxen on formation of stressinduced gastric lesions, the regulation of systemic inflammation, hypoxia and alterations in gastric microcirculation. J Physiol Pharmacol. 2017 Oct 1;68(5):749-756.

7. Ahmad I, Swaroop A, Bagchi D. Protective Ability of Vitamin E Against Acetylsalicylic Acid-Induced Glutathione Depletion, Acetylcholinesterase and (Na+, K+)-ATPase Activities, and Erythrocyte Osmotic Fragility. J Nutr Health Sci. 2018;5(3):308.

8. Modjtahedi BS, Fong DS, Jorgenson E, Van Den Eeden SK, Quinn V, Slezak JM. The relationship between nonsteroidal anti-inflammatory drug use and age-related macular degeneration. American journal of ophthalmology. 2018 Apr 1;188:111-122.

9. Takayama C, de-Faria FM, de Almeida AC, Dunder RJ, Manzo LP, Socca EA, et al. Chemical composition of Rosmarinus officinalis essential oil and antioxidant action against gastric damage induced by absolute ethanol in the rat. Asian Pacific journal of tropical biomedicine. 2016 Aug $1 ; 6(8): 677-681$.

10. Mei H, Tu H. Vitamin $\mathrm{C}$ and Helicobacter pylori infection: current knowledge and future prospects. Frontiers in physiology. 2018 Aug 14;9:1103.

11. Jiang Q. Natural forms of vitamin $E$ as effective agents for cancer prevention and therapy. Advances in Nutrition. 2017 Nov;8(6):850-867.

12. Obembe AO, Ofutet EO, Okpo-Ene AI, Udondian ES. Gastroprotective Role of the Combined Effects of Vitamins $\mathrm{C}$ and E Following Chronic Exposure to Thermoxidized palm oil in Albino Rats.J App Pharm Sci.2015. doi: 10.7324/JAPS.2015.58.S12

13. Goodies ME, Iziegbe OL, Augustine AH, Precious I, Ejiroghene A. Anti-ulcerogenic Activity of Aqueous Extract of Unripe Fruit of Musa sapientum Linn in Combination with Vitamin $\mathrm{C}$ on Ulcer Induced Models in Experimental Rats. European Journal of Medicinal Plants. 2017 Jun 9:1-6. 
14. Gan WC, Smith L, McIntyre E, Steel A, Harnett JE. The prevalence, characteristics, expenditure and predictors of complementary medicine use in Australians living with gastrointestinal disorders: A cross-sectional study. Complementary therapies in clinical practice. 2019 May 1; 35:158-69.

15. Shah D, Nitin M, Rao As. Study of few selected antioxidants, vitamins and minerals using aspirin induced ulcer model in rats. Advances in Pharmacology and Toxicology. 2016 Aug $1 ; 17(2): 41$.

16. Obembe AO, Ofutet EO, Okpo-Ene AI, Udondian ES. Gastroprotective Role of the Combined Effects of Vitamins $\mathrm{C}$ and E Following Chronic Exposure to Thermoxidized palm oil in Albino Rats. Journal of Applied Pharmaceutical Science. 2015;5(2):076-80.
17. Bjarnason I, Scarpignato C, Holmgren E, Olszewski M, Rainsford KD, Lanas A. Mechanisms of damage to the gastrointestinal tract from nonsteroidal antiinflammatory drugs. Gastroenterology. 2018 Feb $1 ; 154(3): 500-514$.

\section{AUTHORS' CONTRIBUTION:}

AA: Conceived, designed, manuscript writing

ST: Supervision, correction in manuscript

RT: Supervision, conceived, manuscript writing and Proof reading 